\title{
Fe-Rich Intermetallic Formation and Mechanical Properties of Recycled AA6111 Alloy Strips Produced by Melt Conditioning Twin Roll Casting
}

\author{
KAWTHER AL-HELAL (i), ${ }^{1,2}$ JAYESH B. PATEL, ${ }^{1}$ and ZHONGYUN FAN ${ }^{1}$ \\ 1.-BCAST, Brunel University London, Uxbridge UB8 3PH, UK. 2.-e-mail: kawther.al- \\ helal2@brunel.ac.uk
}

\begin{abstract}
The impact of high shear melt conditioning on the morphology and distribution of $\mathrm{Fe}$ intermetallic compounds was investigated in the processing of recycled AA6111 alloy by the twin roll casting process. The optical and scanning electron microscope (SEM) micrograph studies were carried out on twin roll casting (TRC) and melt conditioning twin roll casting (MC-TRC) samples. The microstructural analysis showed fine and uniformly distributed Fe-rich intermetallic phases for MC-TRC strips compared with the TRC strips. There was a significant improvement in the mechanical properties of MC-TRC strips after applying melt conditioning. The as-cast MC-TRC samples showed 18.7\%, $19.2 \%$ and $9.8 \%$ increases in elongation, yield strength and ultimate tensile strength, respectively, in the longitudinal direction, while in the transverse section, the MC-TRC samples showed 32.3\%, 2.2\% and 3.8\% increases in elongation, yield strength and ultimate tensile strength, respectively.
\end{abstract}

\section{INTRODUCTION}

Iron is one of the unavoidable impurity elements that exist in primary or secondary aluminium alloys, and it is problematic in recycling aluminium scrap. It is accumulated from the bauxite and tools used during the casting process. Because of its low solubility in aluminium, iron with other impurities forms intermetallic phases such as $\mathrm{Al}_{3} \mathrm{Fe}$, $\alpha$ $\mathrm{Al}_{8} \mathrm{Fe}_{2} \mathrm{Si}, \beta-\mathrm{Al}_{5} \mathrm{FeSi}, \delta-\mathrm{Al}_{4} \mathrm{FeSi}_{2}$ and $\gamma-\mathrm{Al}_{3} \mathrm{FeSi}$. The mechanical properties of aluminium alloys are highly affected by the morphology and distribution of these intermetallic phases. ${ }^{1} \beta-\mathrm{Al}_{5} \mathrm{FeSi}$ Fe-rich intermetallics usually form as faceted large platelets, and this brittle structure causes the loss of strength and ductility of the aluminium alloy, while the $\alpha-\mathrm{Al}_{8} \mathrm{Fe}_{2} \mathrm{Si}$ phase appears with many different types of morphology. With a $\mathrm{Mn} / \mathrm{Fe}$ ratio equal to 0.5 , a body-centred cubic $\alpha-\mathrm{Al}_{15}(\mathrm{Fe}, \mathrm{Mn})_{3} \mathrm{Si}_{2}$ is formed, while different structures appear at other $\mathrm{Mn} / \mathrm{Fe}$ ratios. ${ }^{2}$ Morphological control of these intermetallics, from plate-like to compact shapes or resembling Chinese script, can reduce their detrimental effect on the final mechanical properties. ${ }^{3}$

(Received May 12, 2020; accepted July 31, 2020;

published online August 31, 2020)
Efforts have been made in casting recycled aluminium alloys to control the formation of Fe-rich intermetallics and reduce their harmful impact on the mechanical properties of the final product. It has been found that Fe-rich phases are likely to nucleate on the oxide films entrained in aluminium alloys, and these oxides are normally agglomerated in clusters within the melt. To disperse large oxide films and clusters into very fine and uniformly distributed individual particles, high shear melt conditioning (HSMC) technology, developed at Brunel Centre for Advanced Solidification Technology (BCAST)/Brunel University London, has been used. This technology showed that applying high shear melt conditioning can enhance the nucleation of intermetallic phases and refine their size. ${ }^{4}$

Twin roll casting is an economical industrial process that produces sheets directly from Al-alloy melt. It can accomplish rapid solidification, which can improve the mechanical properties of Al-alloy sheets. ${ }^{5}$ Due to the problem of alloyed materials sticking to the rolls and the development of microstructures with casting defects, which are unacceptable for downstream thermomechanical processing, this type of casting is restricted to processing only a limited number of wrought $\mathrm{Al}-$ 
alloys. In twin roll casting, centreline segregation, macroscopic buckling and surface defects are very common. ${ }^{6}$ To minimize these defects in casting recycled aluminium alloys and improve the quality of the strip, a new technique was tested by using high shear melt conditioning before casting, and the developed process is known as melt conditioning twin roll casting (MC-TRC). ${ }^{7-9}$ In this newly developed technology, a rotor-stator mixer was used to apply intensive melt shearing. This rotor-stator type technology has been tested as a multi-purpose device for degassing, grain refinement, metal matrix composite casting and industrial casting processes such as direct chill casting and twin roll casting. ${ }^{10}$ Because of its advantages in chemical and thermal homogenization, HSMC technology can be used for microstructure control, especially morphological control of $\mathrm{Fe}$-rich intermetallic phases. By dispersing naturally existing oxide particles and enhancing their wettability in the melt, they can act as heterogeneous nuclei during solidification. ${ }^{11}$ In our previous study, we found that by applying HSMC in the casting of AA6111 strips the segregation of intermetallics to the centreline was eliminated with significant improvement in the microstructure and strip quality. ${ }^{8}$

In our previous publication, ${ }^{8}$ we investigated the effect of high shear melt conditioning on the microstructure of recycled AA6111 alloy and the possibility of reducing casting defects such as centreline segregation in casting recycled aluminium alloys in twin roll casting. In this study, we investigated the impact of HSMC on the size and distribution of Fe-rich intermetallic compounds within the recycled AA6111 strips formed by the twin roll casting process and in addition reported the measured mechanical properties of TRC and MC-TRC processed strips.

\section{EXPERIMENTAL PROCEDURES}

\section{Twin Roll Casting}

A horizontal small-scale twin roll caster was used in this study as shown in Fig. 1; the detailed description of this caster was reported in our previous publications. ${ }^{7,8}$ A high shear melt conditioning chamber with a tundish assembly was used to process the recycled aluminium alloy prior to casting into the rolls. The details of the melt feeding chamber assembly with the shearing device have been described in a previous publication ${ }^{9}$ and are shown in the schematic drawing in Fig. S1. The chemical composition of the recycled AA6111 alloy used in the present study is $\mathrm{Al}-0.95 \mathrm{Mg}-0.88 \mathrm{Si}-$ $0.37 \mathrm{Fe}-0.22 \mathrm{Mn}-0.91 \mathrm{Cu}-0.03 \mathrm{Ti}-0.02 \mathrm{Zn}$ (wt.\%), which was supplied by Primetals Ltd. Experiments were conducted with a roll gap of $2.5 \mathrm{~mm}$ for conventional TRC and MC-TRC. The optimum operating conditions for this roll gap were a setback of $35 \mathrm{~mm}$ and roll speed of $3.0 \mathrm{rpm}$. For MC-TRC, the feeding chamber was filled with the alloy melt at $668^{\circ} \mathrm{C}$ prior to adding the melt for continuous operation. The preheated rotor-stator device was inserted at the centre of the chamber and the rotor speed was set at $3000 \mathrm{rpm}$. The measured temperature of the melt at the tundish tip for the conventional TRC and MC-TRC was $\sim 660^{\circ} \mathrm{C}$. AA6111 alloy strips of $3.2-\mathrm{mm}$ as-cast thickness and $110-\mathrm{mm}$ width were successfully cast for conventional TRC and MCTRC.

\section{Metallographic Characterization}

Samples of TRC and MC-TRC strips in longitudinal and transverse directions were sectioned, mounted, ground, and polished following the standard procedure for the metallographic characterization. The polished samples were anodized in Barker's reagent at $20 \mathrm{~V}$ for $90 \mathrm{~s}$ to reveal the grain structure. A Zeiss Axio-Vision optical microscope was used for the microstructural analysis. A Zeiss Supera 35 FEG microscope was used for the scanning electron microscopy (SEM) examination of the samples with accelerating voltage of $20 \mathrm{kV}$.

\section{Mechanical Testing}

Rectangular tensile specimens for conventional TRC and MC-TRC strips were machined. Figure 2 shows the dimensions of the tensile test specimen, which are according to the ASTM B557 M-14 standard. ${ }^{12}$ The thickness of each tensile specimen was $3.2 \mathrm{~mm}$. At least five samples for each casting condition were used for the tensile tests. An Instron 5500 universal electromechanical testing system was used for the mechanical testing at room temperature. This system is equipped with Bluehill software with $a \pm 50 \mathrm{kN}$ load cell and $1 \mathrm{~s}^{-1}$ strain rate.

\section{RESULTS AND DISCUSSION}

\section{Microstructural Analysis}

Optical micrographs in Figs. 3 and 4 show the microstructure and centreline segregation band of recycled AA6111 alloy for the TRC and MC-TRC in longitudinal and transverse directions. As discussed in our previous publication, ${ }^{8}$ the micrographs of the conventional TRC showed large dendritic grains and non-homogeneous microstructure with continuous centreline segregation, while the micrographs of MC-TRC showed homogeneous microstructure with fine and equiaxed grains with discrete centreline segregation.

The segregation of existing solute elements from the surface to the centre of the strip is behind the formation of the segregation band in the centre. The degree of segregation of solutes to the centre and then the internal defects is an indication of the shape of the liquid metal sump. The V-shaped sump means the worse the centreline segregation is, while the flatter the U-shaped sump is, the better the twin roll casting conditions. The solidification 

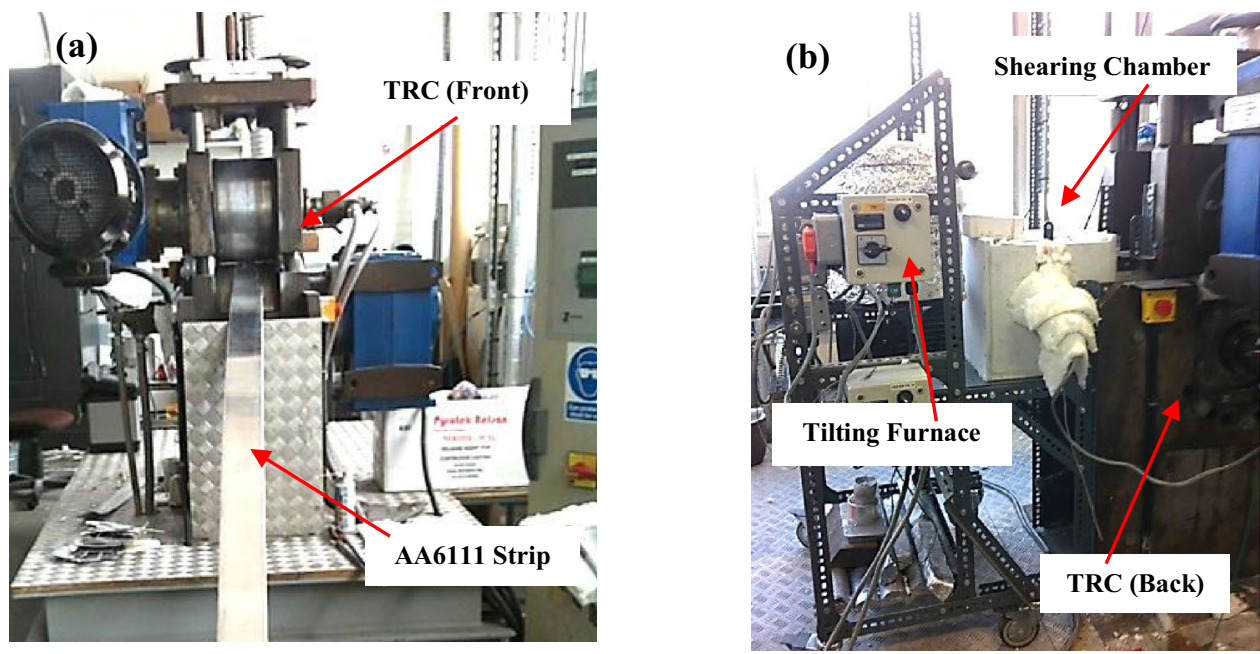

Fig. 1. (a) Horizontal twin roll caster (front view); (b) feeding chamber with tilting furnace assembly for twin roll casting machine (side view).

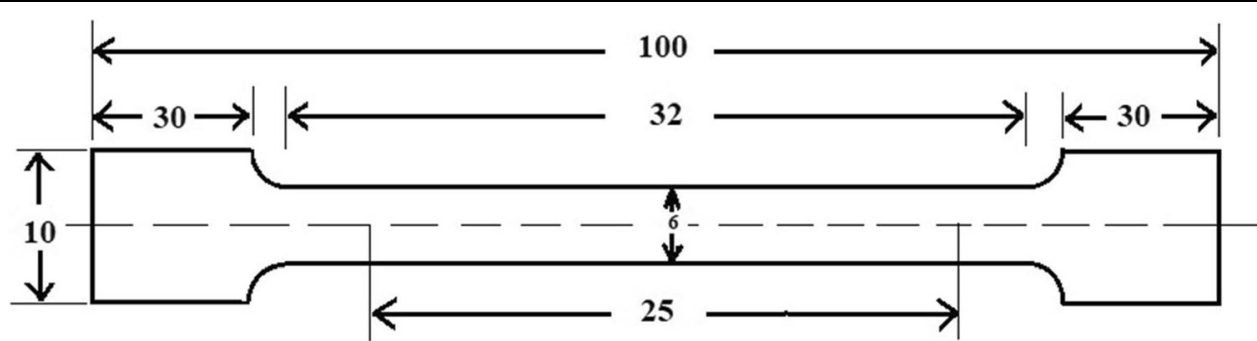

Fig. 2. Dimensions in $\mathrm{mm}$ of the rectangular tensile test specimen according to the ASTM B557 M-14 standard. Adapted from Ref. 12.

mechanism in casting with HSMC is believed to be a heterogeneous nucleation utilising the existed oxide particles as a substrate. This will reduce the segregation of solutes towards the centre and enhance the formation of an equiaxed solidification front across the whole section. Therefore, the sump depth will decrease and the depth of deformation region will increase. Figure $3 \mathrm{~b}$ shows that the degree of deformation of strips produced with MCTRC was high and accordingly the mechanical properties of the final product improved. ${ }^{9}$

Applying intensive melt shearing prior to casting enhances the oxide particles and clusters to make them potent nucleating sites to refine $\alpha$-Al phase and intermetallic phases. ${ }^{13}$ During normal casting of aluminium alloys, the oxide bifilms or discrete oxides particles can be entrained into the casting from the oxide film formed at the melt surface. ${ }^{14}$ Intensive melt shearing disperses oxides films and clusters uniformly throughout the liquid metal. It is well known that the formed oxide in $\mathrm{Al}-\mathrm{Mg}$ alloys is spinel $\mathrm{MgAl}_{2} \mathrm{O}_{4}$ and its lattice misfit with $\alpha$-Al is around $1.4 \% .^{15}$ Therefore, spinel particles will be potent nucleation sites for $\alpha$-Al phase for a melt with shortage in nucleating particles. ${ }^{16}$ This potent particles will lead to a refined equiaxed grain structure with reduced centreline segregation. ${ }^{9}$

\section{Fe-Rich Intermetallic Size and Distribution}

The phase diagram of the as-received AA6111-xFe alloy at equilibrium was calculated using Pandat software; see supplementary Fig. S2. In casting AA6111 with 0.37 wt.\% $\mathrm{Fe}$, the intermetallic phase forms are $\alpha-\mathrm{Al}_{15}(\mathrm{Fe}, \mathrm{Mn})_{3} \mathrm{Si}_{2}, \mathrm{Mg}_{2} \mathrm{Si}$ and $\beta$-AlFeSi. The plate-like $\beta$-AlFeSi is a brittle phase and acts as a stress raiser and weak point in coherence, which can lead to local crack initiation and reduce the mechanical properties of the strip. ${ }^{17}$ In $\mathrm{Al}-\mathrm{Mg}-\mathrm{Si}$ alloys containing $\mathrm{Mn}$, the structure of the $\alpha-\mathrm{Al}_{15}(\mathrm{Fe}$, $\mathrm{Mn})_{3} \mathrm{Si}_{2}$ intermetallic is body-centred cubic, which may appear as hexagonal, star-like or dendritic crystals at different $\mathrm{Mn} / \mathrm{Fe}$ ratios. Morphological control of this intermetallic from plate-like to compact shapes or resembling Chinese script can reduce its detrimental effect on the final mechanical properties. ${ }^{18}$ It is well known that the formation of Ferich phases can block the interdendritic flow regions and results in high-porosity products. ${ }^{19}$

The morphology of intermetallic phases at the centreline region for conventional TRC and MCTRC is shown in Fig. 5 . The plate-like $\beta$-AlFeSi phase typically formed during TRC has been observed at the centreline region and has been refined to a more compact morphology after MCTRC as shown in Fig. 5b. 

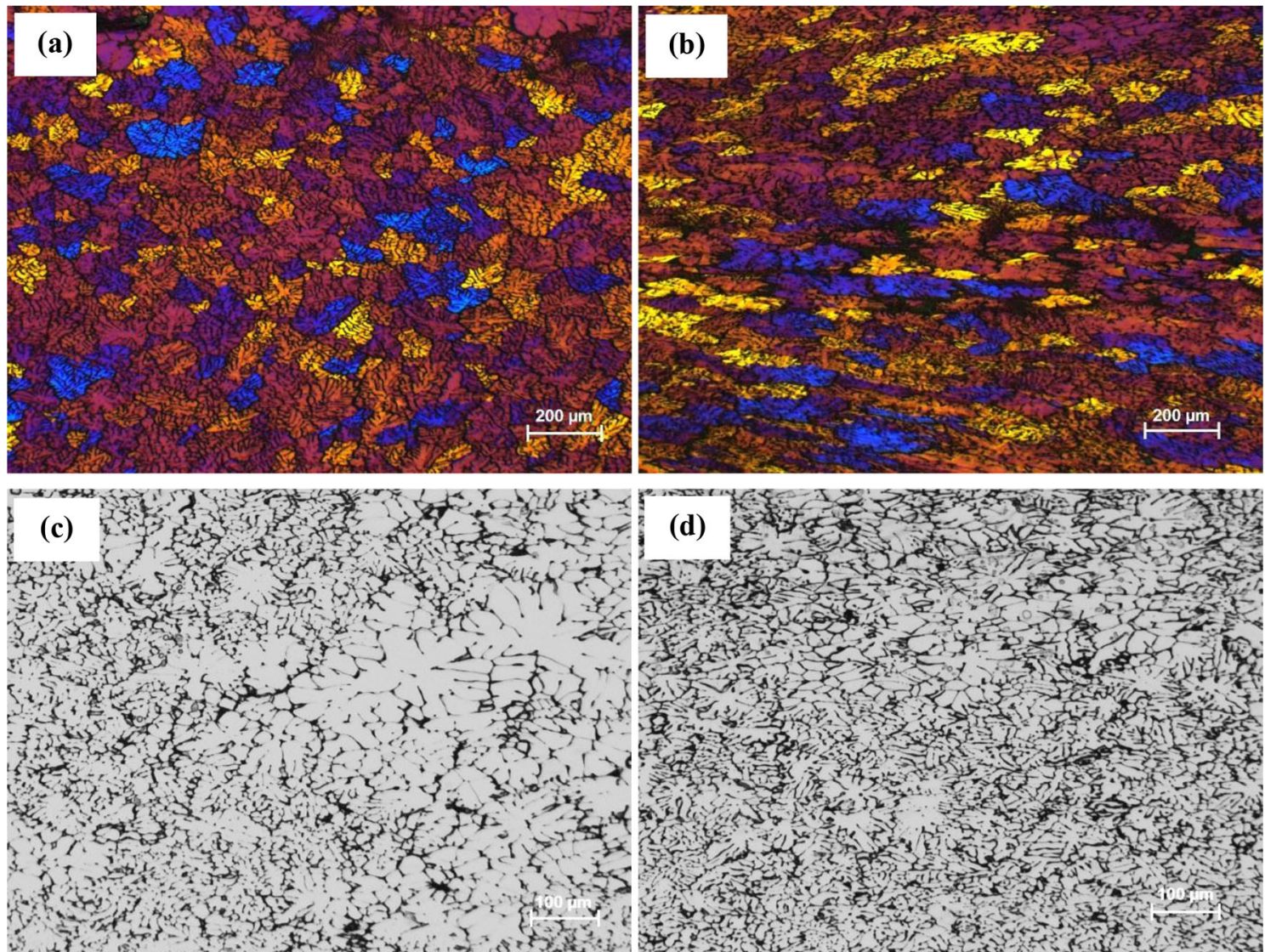

Fig. 3. As-cast microstructure of recycled AA6111 alloy: (a, b) TRC and MC-TRC in longitudinal direction; (c, d) TRC and MC-TRC in transverse direction.

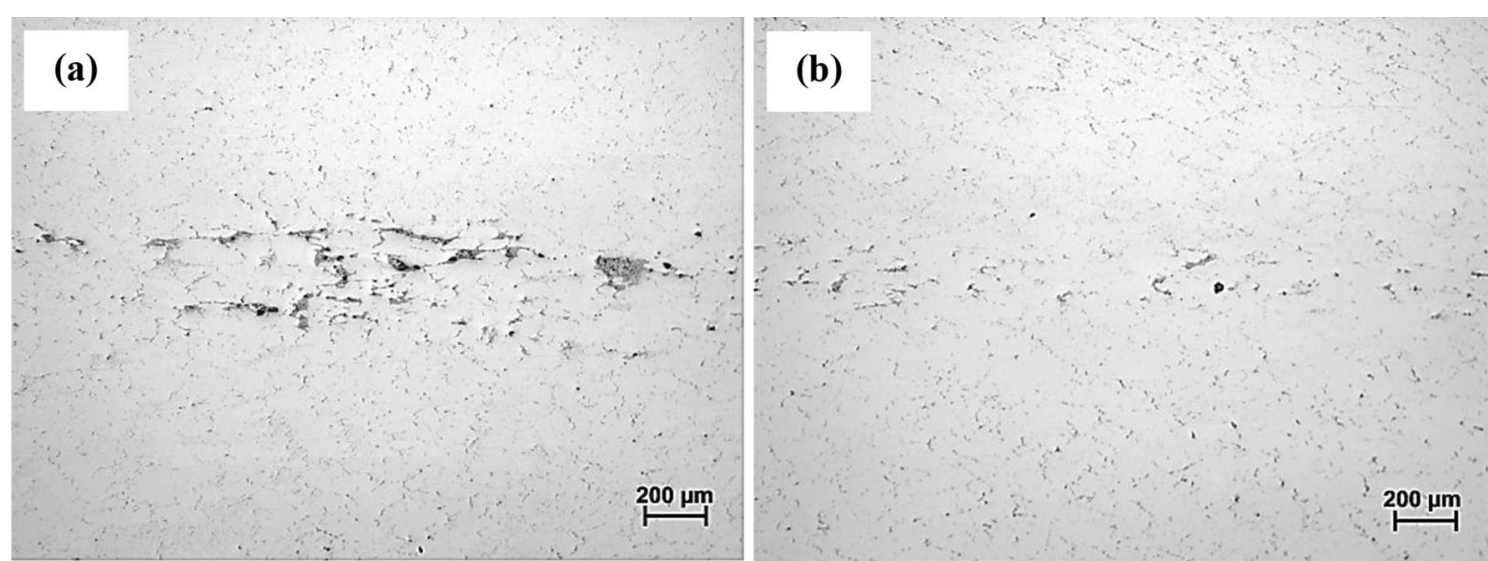

Fig. 4. Centreline segregation band of recycled AA6111 alloy in longitudinal direction: (a) TRC; (b) MC-TRC.

It is clear that using intensive melt shearing refined the size of Fe-rich phases and helped the uniform distribution of these intermetallic phases. Figure 6 shows the size and distribution of intermetallic phases within the matrix of TRC and MCTRC in casting recycled AA6111 alloy. The breakup and dispersion of oxide bifilms and clusters help refine the $\mathrm{Fe}$-rich intermetallic and change its morphology. It has been found that oxide particles such as $\mathrm{MgO}, \mathrm{Al}_{2} \mathrm{O}_{3}$ and $\mathrm{MgAl}_{2} \mathrm{O}_{4}$ are similar to $\mathrm{TiB}_{2}$, and heterogeneous nucleation can occur in nucleating $\mathrm{Fe}$ intermetallics. ${ }^{20}$ This improves the microstructure and prevents the negative influences of a large plate-like morphology of $\beta-\mathrm{AlFeSi}$ 

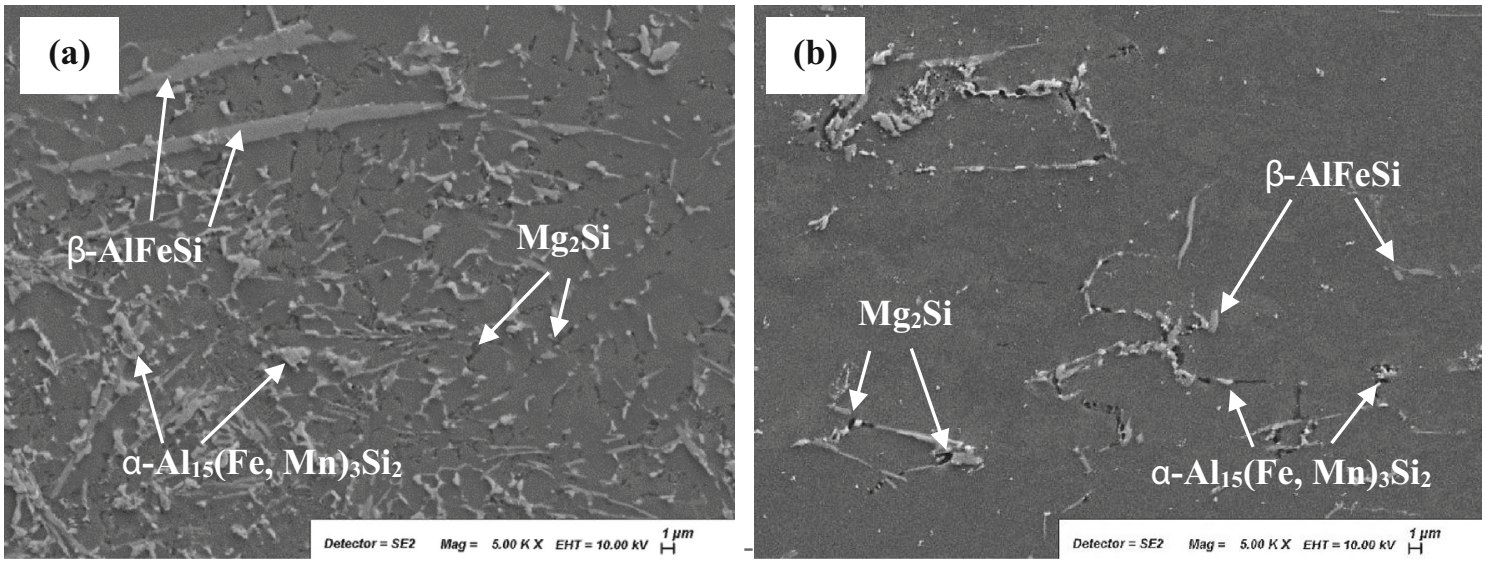

Fig. 5. SEM micrographs showing the morphology of the intermetallic at the centreline segregation band of as-cast recycled AA6111 alloy: (a) conventional twin roll casting TRC and (b) melt conditioning twin roll casting MC-TRC.
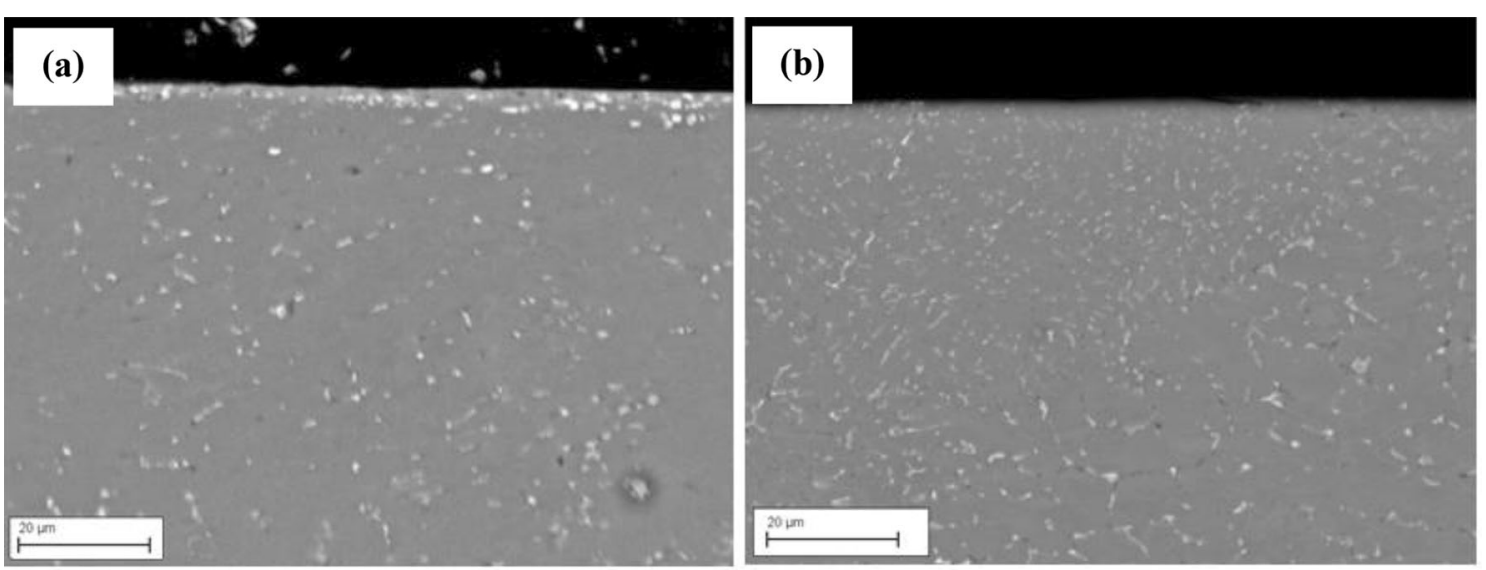

Fig. 6. Scanning electron microscopy (SEM) micrographs of recycled AA6111 alloy in the longitudinal direction showing: (a) the microstructure of TRC and (b) size and distribution of Fe-rich intermetallic of MC-TRC.

intermetallic phase on the mechanical properties of the casting product. In addition to centreline segregation, Fig. $6 \mathrm{a}$ shows a surface segregation of the intermetallic in conventional TRC, which is one of the casting defects. The reason for this type of defect is the squeezing of solute-enriched liquid from the mushy zone towards the surface through the interdendritic region. When productivity exceeds casting speed, the enriched liquid in the interdendritic regions will connect together and form a transport path, and due to presence of low pressure zones at the surface, the enriched liquid flows towards the surface through these paths. ${ }^{21}$ In case of MC-TRC, the solute and heat distribution within the melt is homogeneous, and this will eliminate centreline and surface segregation. Casting without internal and surface defects can improve the strip quality and subsequently its mechanical properties.

\section{Mechanical Properties}

The tensile properties of conventional TRC and MC-TRC strips of recycled AA6111 alloy in the longitudinal and transverse direction are shown in
Fig. 7. As shown in Table I, the tensile properties of AA6111 strips processed by MC-TRC have a significant increase in the longitudinal and transverse sections compared to conventional TRC. The MCTRC samples showed $18.7 \%, 19.2 \%$ and $9.8 \%$ increases in elongation, yield strength and ultimate tensile strength, respectively, in the longitudinal direction, while in the transverse direction, the test showed $32.3 \%, 2.2 \%$ and $3.8 \%$ increases in elongation, yield strength and ultimate tensile strength, respectively, compared to the TRC.

The mechanical behaviour of the alloy mainly depends on its grain size and microstructure. In this study, we found that applying the high shear melt conditioning improved the microstructure, eliminated centreline and surface segregation and finally improved the mechanical properties. Normally, the increase of strength occurs with the decrease of ductility properties, but with the homogeneous distribution of fine grains and elimination of casting defects such as centreline segregation, both the strength and ductility can be increased. ${ }^{7}$ The refinement of the intermetallic phases reduces the probability of these particles tearing the matrix 

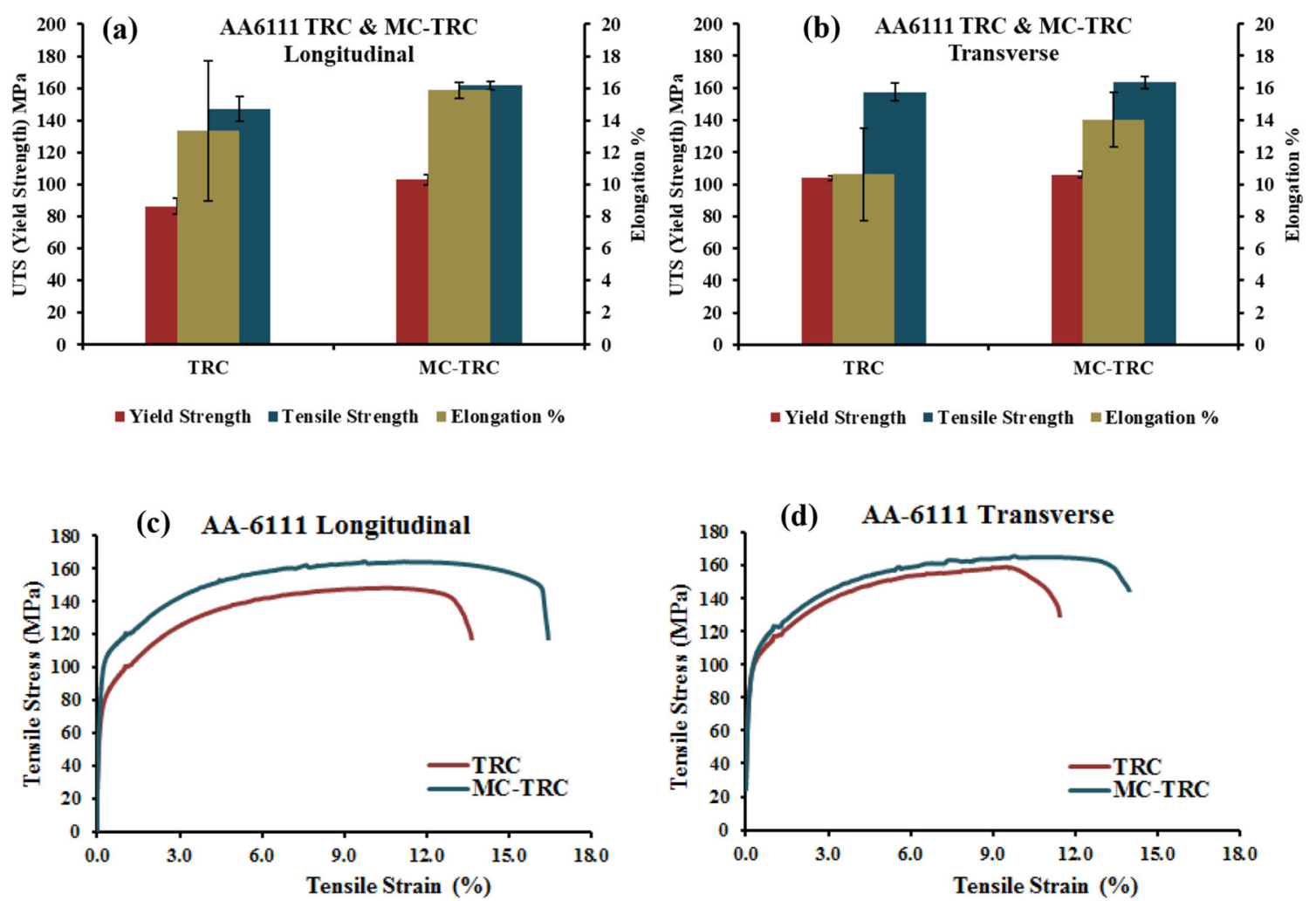

Fig. 7. Mechanical properties of recycled AA6111 strips processed from TRC and MC-TRC casting; (a, c) longitudinal direction and (b, d) transverse direction.

Table I. Mechanical properties of recycled AA6111 alloy for TRC and MC-TRC in different casting directions

\begin{tabular}{|c|c|c|c|c|c|c|}
\hline \multirow{2}{*}{$\begin{array}{l}\text { Direction } \\
\text { Mechanical } \\
\text { properties }\end{array}$} & \multicolumn{3}{|c|}{ Longitudinal } & \multicolumn{3}{|c|}{ Transverse } \\
\hline & $\begin{array}{c}\text { Elongation } \\
(\%)\end{array}$ & $\begin{array}{c}\text { Yield } \\
\text { strength } \\
\text { (MPa) }\end{array}$ & $\begin{array}{c}\text { Ultimate } \\
\text { strength (MPa) }\end{array}$ & $\begin{array}{c}\text { Elongation } \\
(\%)\end{array}$ & $\begin{array}{c}\text { Yield } \\
\text { strength } \\
\text { (MPa) }\end{array}$ & $\begin{array}{c}\text { Ultimate } \\
\text { strength (MPa) }\end{array}$ \\
\hline TRC & $13.4 \pm 4.4$ & $86.3 \pm 4.9$ & $147.2 \pm 7.8$ & $10.6 \pm 2.9$ & $103.7 \pm 1.3$ & $157.5 \pm 5.4$ \\
\hline MC-TRC & $15.7 \pm 0.5$ & $102.9 \pm 3.1$ & $161.6 \pm 2.5$ & $14.1 \pm 1.7$ & $106.1 \pm 1.8$ & $163.5 \pm 3.8$ \\
\hline
\end{tabular}

under applied stress, which leads to the maintenance of intrinsic fracture stress.

In conclusion, the MC-TRC processed strip shows superior ultimate tensile strength and ductility. Applying intensive melt shearing enhanced the dispersion of the oxide films and clusters, which resulted in efficient nucleation of Fe-rich intermetallic phases and casting in refined particles. This refinement increases iron tolerance in recycled aluminium alloy and improves its mechanical properties. ${ }^{4}$

The tensile test for MC-TRC showed that the elongation for the longitudinal direction was $13 \%$ higher and the yield strength and ultimate tensile strength were lower by $3.1 \%$ and $1.2 \%$, respectively, compared to the transverse direction. Okayasu et al. ${ }^{22}$ found that the mechanical properties of aluminium alloy sheets were controlled by the anisotropic microstructure that formed during sheet rolling. The casting conditions in twin roll casting such as roll speed, cooling rate and melt temperature are the most effective parameters for the formation of the anisotropic microstructure. It is well known that plastic anisotropy is developed during the rolling and heat treatment of aluminium alloy sheets, so more work is needed to test how HSMC affects the texture and improves the plastic anisotropy of recycled AA6111 alloy. 


\section{CONCLUSION}

The impacts of high shear melt conditioning on the morphology and distribution of Fe-rich intermetallic phases and the mechanical properties of recycled AA6111 strips formed by twin roll casting processes were investigated. From microstructural analysis along with mechanical properties measurements, we found that:

1. Applying intensive melt shearing during twin roll casting enhanced the casting process and improved the quality of strips produced from recycled materials.

2. Microstructural analysis of MC-TRC samples showed a refined microstructure with less surface and centreline segregation of Fe-rich intermetallic. This improvement can increase the tolerance for impurities in recycled materials.

3. The plate-like $\beta$-AlFeSi that appeared with conventional TRC was refined to a more compact morphology after applying intensive melt shearing.

4. Using intensive melt shearing refined the size of Fe-rich phases and helped in the uniform distribution of these intermetallic phases within the matrix.

5. A significant increase in tensile properties with MC-TRC was observed for the longitudinal and transverse sections. The as-cast MC-TRC samples showed $18.7 \%, 19.2 \%$ and $9.8 \%$ higher elongation, yield strength and ultimate tensile strength, respectively, in the longitudinal direction compared to conventional TRC, while for the transverse direction, the test results were $32.3 \%, 2.2 \%$ and $3.8 \%$ higher in elongation, yield strength and ultimate tensile strength, respectively.

\section{ACKNOWLEDGEMENTS}

The financial support from Primetals Technologies, UK, is acknowledged with gratitude.

\section{CONFLICT OF INTEREST}

The authors declare that they have no conflict of interest.

\section{OPEN ACCESS}

This article is licensed under a Creative Commons Attribution 4.0 International License, which permits use, sharing, adaptation, distribution and reproduction in any medium or format, as long as you give appropriate credit to the original author(s) and the source, provide a link to the Creative Commons licence, and indicate if changes were made. The images or other third party material in this article are included in the article's Creative Commons licence, unless indicated otherwise in a credit line to the material. If material is not included in the ar- ticle's Creative Commons licence and your intended use is not permitted by statutory regulation or exceeds the permitted use, you will need to obtain permission directly from the copyright holder. To view a copy of this licence, visit http://creativecom mons.org/licenses/by/4.0/.

\section{ELECTRONIC SUPPLEMENTARY MATERIAL}

The online version of this article (https://doi.org/ 10.1007/s11837-020-04324-z) contains supplementary material, which is available to authorized users.

\section{REFERENCES}

1. L. Zhang, J.G. Lucas, N.W. Damoah, and G.R. David. Miner. Process. Extract. Metall. Rev. 33, 99 (2011).

2. S. Ji, W. Yang, F. Gao, D. Watson, and Z. Fan, Mater. Sci. Eng. A 564, 130 (2013).

3. P. Ashtari, H. Tezuka, and T. Sato, Scr. Mater. 53, 937 (2005).

4. J. Lazaro-Nebreda, J.B. Patel, I.T. Chang, I.C. Stone, and Z. Fan, Solidification processing of scrap Al-alloys containing high levels of Fe, in IOP Conference Series: Materials Science and Engineering (2019).

5. T. Haga, M. Ikawa, H. Watari, K. Suzuki, and S. Kumai, Mater. Trans. 46, 2596 (2005).

6. J. Hunt, M. Yun, S. Lockyer, and M. Heywood, Light Metals, 341 (1997).

7. K. Al-Helal, I. Chang, J.B. Patel, and Z. Fan, JOM 71, 2018 (2019).

8. K. Al-Helal, J.B. Patel, and Z. Fan, JOM 71, 1714 (2019).

9. N.S. Barekar, S. Das, X. Yang, Y. Huang, O.E. Fakir, A.G. Bhagurkar, L. Zhou, and Z. Fan, Mater. Sci. Eng. A 650, 365 (2016).

10. K. Al-Helal, J. Lazaro-Nebreda, J.B. Patel, G. Scamans, and Z. Fan, Recycling 4, 37 (2019).

11. J.B. Patel, H.T. Li, M.X. Xia, S. Jones, S. Kumar, K. O'Reilly, and Z. Fan, Mater. Sci. Forum 794-796, 149 (2014).

12. Designation, A. B 557M-02a, Standard Test Methods of Tension Testing Wrought and Cast Aluminum- and Magnesium-Alloy Products [Metric] 2003.

13. H.T. Li, Y. Wang, and Z. Fan, Acta Mater. 60, 1528 (2012).

14. J. Campbell, Metall. Mater. Trans. B 37, 857 (2006).

15. Z.Y. Fan, and B. Jiang, Mater. Sci. Forum, 690, 141 (2011).

16. M.X. Zhang, P.M. Kelly, M. Qian, and J.A. Taylor, Acta Mater. 53, 3261 (2005).

17. L. Zhang, J. Gao, L.N. Damoah, and D.G. Robertson, Miner. Process. Extr. Metall. Rev. 33, 99 (2012).

18. P. Snopiński, M. Król, T. Tański, and B. Krupińska, J. Therm. Anal. Calorim. 133, 379 (2018).

19. T.O. Mbuya, B.O. Odera, and S.P. Ng'ang'a, Int. J. Cast Met. Res. 16, 451 (2003).

20. S. Kumar and K.A. O'Reilly, Mater. Charact. 120, 311 (2016).

21. B. Forbord, B. Andersson, F. Ingvaldsen, O. Austevik, J.A. Horst, and I. Skauvik, Mater. Sci. Eng. A 415, 12 (2006).

22. M. Okayasu, R. Sato, S. Takasu, A. Niikura, and T. Shiraishi, Mater. Sci. Eng. A 534, 614 (2012).

Publisher's Note Springer Nature remains neutral with regard to jurisdictional claims in published maps and institutional affiliations. 